\title{
An automatic Time Table Generation
}

\section{KV Prasad Reddy ${ }^{1}$, B. Thandava Krishna², T. Nithin Sai², YT. Surekha², G. Kowsalya², \\ K. Damodhar Reddy ${ }^{2}$}

${ }^{1}$ Associate Professor\& HOD, Department of Computer Science and Engineering, Sanskrithi School of Engineering, Puttaparthi, Andhra Pradesh, India

2B.TECH. Student, Department of Computer Science and Engineering, Sanskrithi School of Engineering, Puttaparthi, Andhra Pradesh, India

\section{ABSTRACT}

Article Info

Volume 8, Issue 3

Page Number : 831-835

\section{Publication Issue}

May-June-2021

\section{Article History}

Accepted : 12 June 2021

Published : 22 June 2021
The manual system of preparing time table in colleges is very time consuming and Monotonous task which usually ends up with various classes clashing either at identical room or with same teachers having more than one class at a time. To slove all these problems we developing an automated system with computer assisted timetable generator. This system provides a simple interface for generating the timetable automatically. It can be used by educational institutes or colleges to view their timetable in most efficient and easy manner. Keywords : Diabetes, Medicinal Plant, Hypertension, Blood Glucose Level

\section{INTRODUCTION}

Even though most college administrative work as been computerized, the lecture timetable scheduling is still mostly done manually due to its inherent difficulties. The manual lecture timetable scheduling demands considerable time and efforts. The lecturetimetable scheduling is a Constraint satisfaction problem in which we find a solution that satisfies the given set of constraint. Automatic Timetable Generator is a JAVA based software used to generate timetable automatically. Currently timetable is managed manually.It will help to manage all the periods automatically. It maximum and minimum work load for a faculty for a day and week will be specified for the efficient generation of timetable. Timetable scheduler targets to develop software for college in order to handle the 'Timetable Formation' for the staff.

\section{OBJECTIVE:}

This proposed systematist identifying the System will take various task like number of subjects, number of teachers, maximum number of class a teacher can conduct, priority of subject and topics to be covered in a week or a number of class, depending upon these inputs it will generate possible time tables for working days of the week. It mainly focuses on presenting information in an easy and intelligible 
manner which provides easy to viewing the student timetable and staff time table separately.

\section{EXISTING SYSTEM}

The timetabling is a multi-dimensional assignment problem, in which students and lecturers are assigned to courses and events are assigned to classrooms and timeslots .The events are usually meeting between people at a particular location, Educational timetabling is the sub-class of timetabling and the event in this sub-class for example can be: Lecturers in course offered at university. Normally timetable generation done manually.

\section{DRAWBACKS:}

Inconsistency in data entryroom for errors.Time consuming and costly to produce reports.Lack of security.

\section{PROPOSEDSYSTEM}

Automatic Timetable manager is a JAVA based software used to generate timetable automatically. Will help you manage all the periods automatically. Proposed system will help to generate it automatically and also help to save time. There is no need for faculty to worry about their period details and maximum workload. It is a comprehensive timetable management solution for colleges which helps to overcome the challenges in current system

\section{ADVANTAGES:}

1.There is a chance to use the proper time and nousage if human efforts.

2.It is error free.

3.Substitution management made easy.

4.Generate records easily

\section{LITERATURESURVEY}

In our literature survey, we underscore the system refines the lists of concepts through removing those that appear to be of little value and don't have significant meaning in the matching process. By this we mean concepts that express features suchas : Student's name, address, contact info, etc. address, contact info Next, the third module of the proposed system takes the refined lists ofconceptsasinputtoconstructsemanticnetworksinwhi chconceptsareconnectedby various types of semantic.

Literature Review on Timetable generation algorithms based on Genetic Algorithm and Heuristic approach Anisha Jain, Ganapathy S C Aiyer, Harshita Goel, Rishabh Bhandari.

The problem of timetable scheduling is described as a highly constrained NP-hard problem. It is known as the timetabling problem by most researchers.

1. Planning timetable is one of the most complex and error prone task.

2. A lot of complex constraints need to be addressed for development of an efficient algorithm to solve this problem.

ThereviewrevealsthatHRMconstitutesanoteworthyne wdomainofdatamining research that is dominated by method and technology-oriented work. However, specific domain requirements, such as evaluating the domain successor complying with legal standards, are frequently not recognize do considered in current research. Therefore, the systematic consideration of domain specific requirements is demonstrated here to have significant implications for future research on datamining in HRM.

[1].A TimeTable Generation Vikas Gawade, KunalDeokar, Prasanna Retherekar, Shrinath Bhegade, Prof A.D. Bhosale

In this research, the data considered is obtained from the soil testing laboratory in Jabalpur. Two classification algorithm: KNNand NaïveBayes are used for classifying the soil fertility into low, medium and 
high and based on the fertility classified the crops will be predicted.

These constraints can be replicated in a format that can be organized in a systematic manner through a scheduling algorithm. Scheduling involves the use of multiple path restrictions, which can be used to complete tasks. For example, when scheduling classes at an institution, a single time slot is not assigned to a single faculty member who teaches two courses. On the other hand, two different courses should not be distinguished for participation by the same group of students.

[2]Literature Review on Timetable generation algorithms based on Genetic Algorithm and Heuristic approach Anisha Jain, Ganapathy S C Aiyar, Harshita Goel, Rishabh Bhandari

The system will take various task like number of subjects, number of teachers, maximum number of class a teacher can conduct, priority of subject and topics to be covered in a week or a number of class, depending upon these inputs it will generate possible time tables for working days of the week. It mainly focuses on presenting information in an easy and intelligible manner which provides easy to viewing the student timetable and staff time table separately. Creation of timetable thus reducing paper work and automating the generation process in an education.

Even though most college administrative work as been computerized, the lecture timetable scheduling is still mostly done manually due to its inherent difficulties. The manual lecture timetable scheduling demands considerable time and efforts. The lecturetimetable scheduling is a Constraint satisfaction problem in which we find a solution that satisfies the given set of constraint. Automatic Timetable Generator is a JAVA based software used to generate timetable automatically. Currently timetable is managed manually.It will help to manage all the periods automatically. It maximum and minimum work load for a faculty for a day and week will be specified for the efficient generation of timetable.

\section{USECASEDIAGRAM:}

Use case diagram swhich are model behavior within a system and helps the developers to understand of what the user require. Its purpose is to present a graphical overview of the functionality provided by a system in terms ofactors, their goals (represented as use cases), andany dependencies between those use cases. Themain purpose of a use case diagram is to showwhat system functions are performed for whichactor. Roles of the actors in the system can bedepicted. The stick man represents what's calledanactor. Usecase diagram can beuseful for getting an over all view of the system and clarifying who can do and more importantly what they can'tdo.
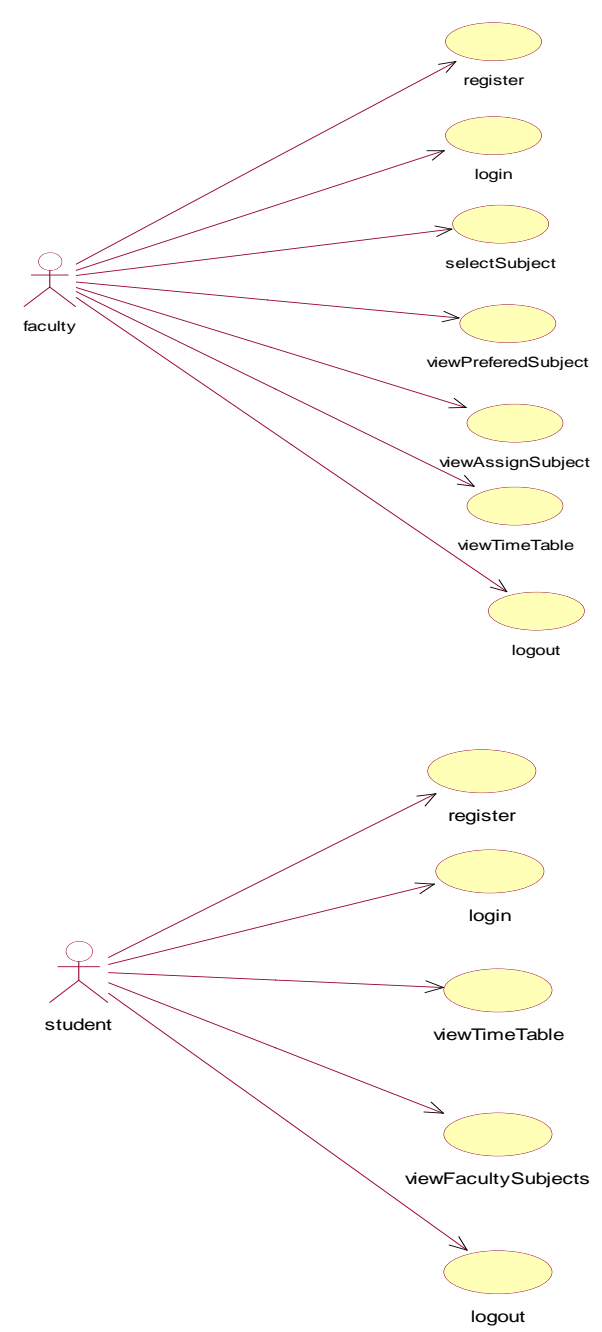


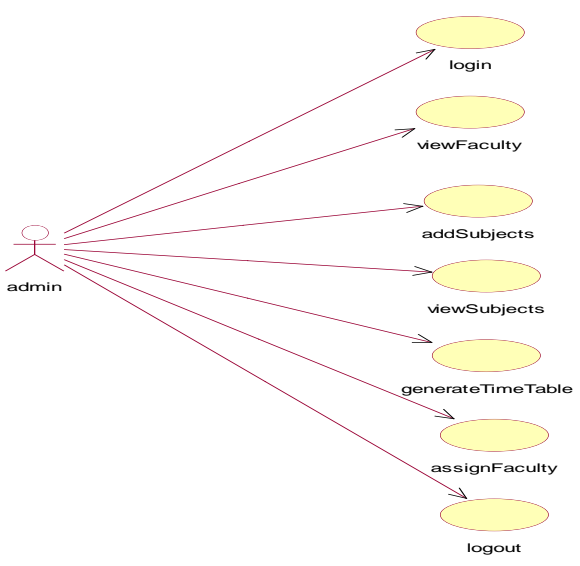

SYSTEM REQUIREMENTS

Software Requirements:

Operating System: Windows 7/8/10

Application Server: Tomcat 7.0

Front End: HTML, JSP

Scripts: JavaScript.

Server-sideScript: Java Server Pages.

Database: My SQL 6.0

Database Connectivity: JDBC

Hardware Requirements:

Processor-I3/Intel Processor

RAM- 4GB (min)

Hard Disk-160GB

KeyBoard-StandardWindows Keyboard

Mouse - Two or Three Button Mouse

\section{BLOCKDIAGRAM:}

This block diagrams explains about how there curettement process can be done through our proposed system.

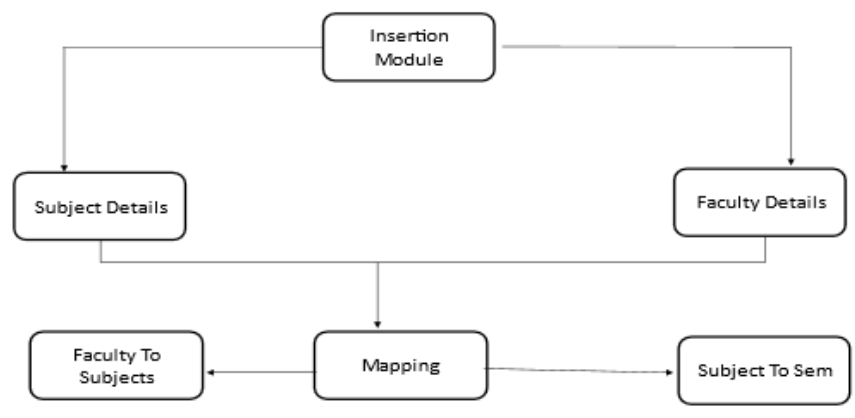

\section{Results}

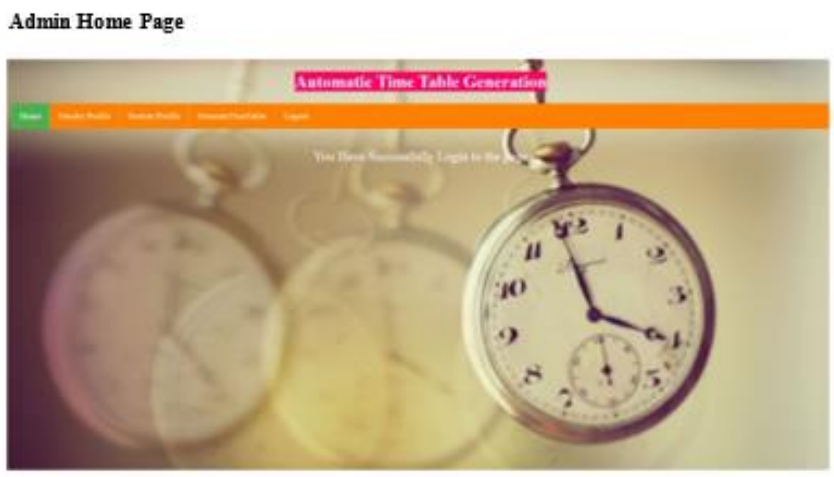

Admin Login Page:

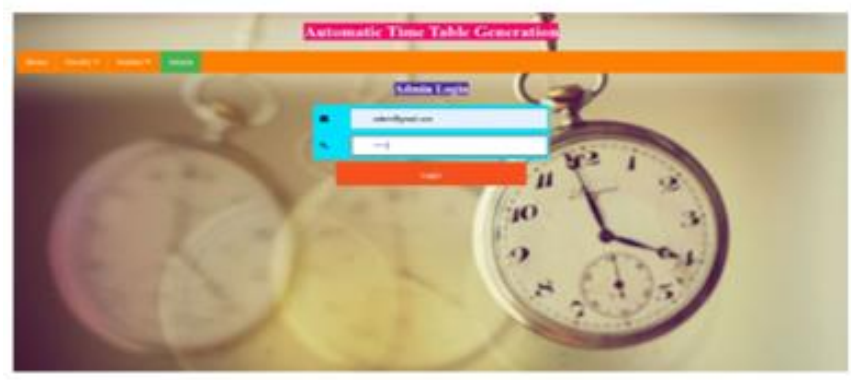

Student $\log$ in

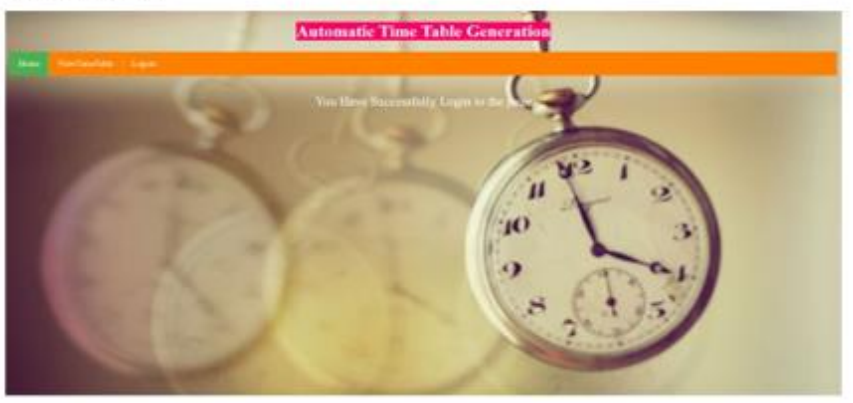

Admin Faculty Update Page:

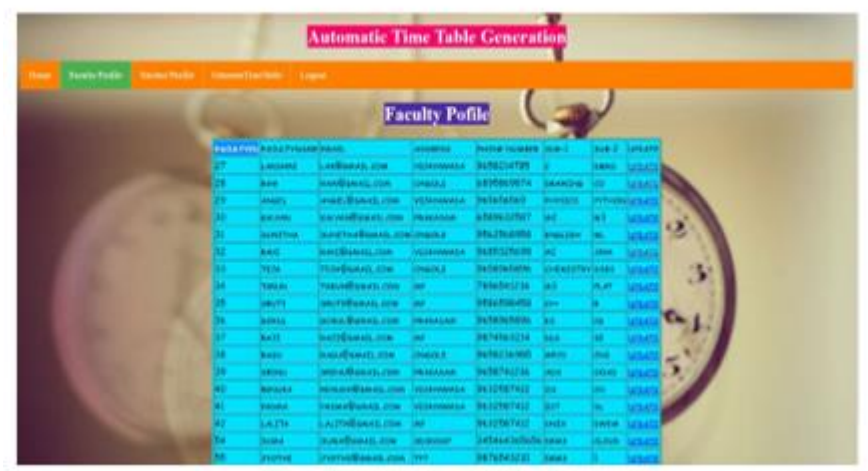




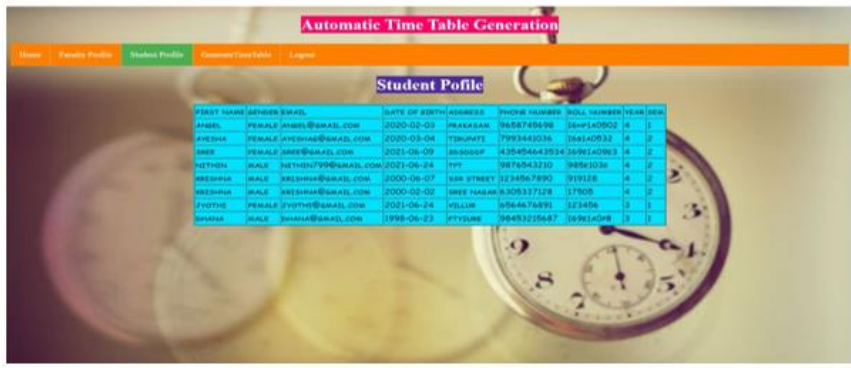

Admin Generate Time Table Page

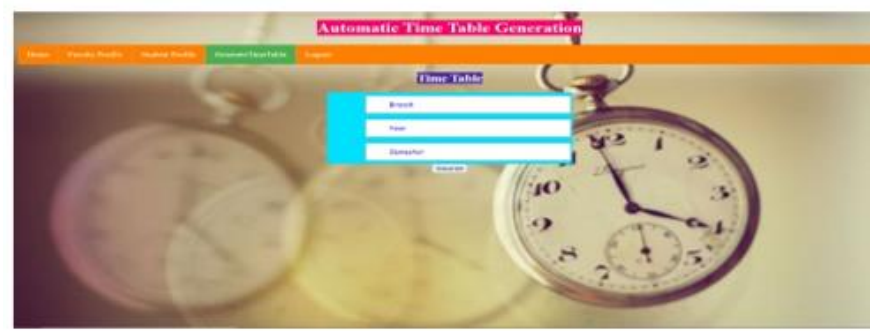

VI. Conclusion

The application will make the procedure of time table generation easier consistently which may otherwise need to be done using spread sheet manually which might lead to constraints problem that are strenuous to establish when time table is generated physically. The purpose of the algorithm is to generate a timetable schedule mechanically. The algorithm includes many techniques, aimed at improving the efficiency of the search operation. It also addresses the chief hard constraints. Most of the non-rigid soft constraints are also productively handled. Keeping in mind the generality of the algorithm operation, it can further be modified to more particular scenarios, e.g. University, examination scheduling, etc. A number of hours which are spent on creating a fruitful timetable can be reduced ultimately through the mechanization of the timetable issue. The most fascinating future direction in the evolution of the algorithm lies in its addendum to constraint propagation.

\section{FUTUREENHANCEMENT}

Further we can add up features like Live video sessions for further interview rounds by maintain social distance.

\section{REFERENCES}

[1]. Anirudha Nanda, Manisha P. Pai, and Abhijeet Gole (August 2012), An Algorithm to Automatically Generate Schedule for School Lectures Using a Heuristic Approach, International Journal of Machine Learning and Computing, Vol. 2, No.2 .

[2]. M.Mochol,H.WacheandL.Nixon,"Improving the Accuracy of Job Searchwith Semantic Techniques"

BusinessInformationSystems,SpringerBerlinHei delberg,pp.301-313, 2007.

[3]. MasriAyob, Salwani Abdullah and Ariff Md Ab Malik (September 2007), A Practical Examination Timetabling Problem at the UniversitiKebangsaan Malaysia, IJCSNS International Journal of Computer Science and Network Security, Vol.7 No.

[4]. Bhaduri a "university timetable scheduling using genetic algorithm". Advances in Recent Technologies in Communication and Computing, 2009. ARTCom '09. International Conference

[5]. DiptiShrinivasan "automated time table generation using multiple context reasoning for university modules" Published in: evolutionary computation, 2002. cec ' 02 . proceedings of the 2002 congress on (volume:2 )

[6]. AnujaChowdhary "TIME TABLE GENERATION SYSTEM” .Vol.3 Issue.2, February- 2014, pg. 410414

[7]. Anirudha Nanda "An Algorithm to Automatically Generate Schedule for School Lectures Using a Heuristic Approach".International Journal of Machine 
Learning and Computing, Vol. 2, No. 4, August 2012.

[8]. A. Elkhyari, C. Gu'eret, and N. Jussien, "Solving dynamic timetabling problems as dynamic resource constrained project scheduling problems using new constraint programming tools. In Edmund Burke and Patrick De Causmaecker, editors, Practice And Theory of Automated Timetabling, Selected Revised Papers," pp. 39-59. Springer- Verlag LNCS 2740, 2003.

\section{Cite this article as :}

KV Prasad Reddy, B. Thandava Krishna, T. Nithin Sai, YT. Surekha, G. Kowsalya, K. Damodhar Reddy, " An automatic Time Table Generation", International Journal of Scientific Research in Science and Technology(IJSRST), Print ISSN : 2395-6011, Online ISSN : 2395-602X, Volume 8, Issue 3, pp.831-835, May-June-2021. Available at doi : https://doi.org/10.32628/IJSRST2183183 Journal URL : https://ijsrst.com/IJSRST2183183 